This item was submitted to Loughborough's Research Repository by the author.

Items in Figshare are protected by copyright, with all rights reserved, unless otherwise indicated.

\title{
LQG control for the integrated tilt and active lateral secondary suspension in high speed railway vehicles
}

PLEASE CITE THE PUBLISHED VERSION

http://dx.doi.org/10.1109/ICCA.2010.5524239

PUBLISHER

(C) IEEE

VERSION

VoR (Version of Record)

LICENCE

CC BY-NC-ND 4.0

\section{REPOSITORY RECORD}

Zhou, Ronghui, Argyrios C. Zolotas, and Roger M. Goodall. 2019. "LQG Control for the Integrated Tilt and Active Lateral Secondary Suspension in High Speed Railway Vehicles”. figshare.

https://hdl.handle.net/2134/6630. 
This item was submitted to Loughborough's Institutional Repository (https://dspace.lboro.ac.uk/) by the author and is made available under the following Creative Commons Licence conditions.

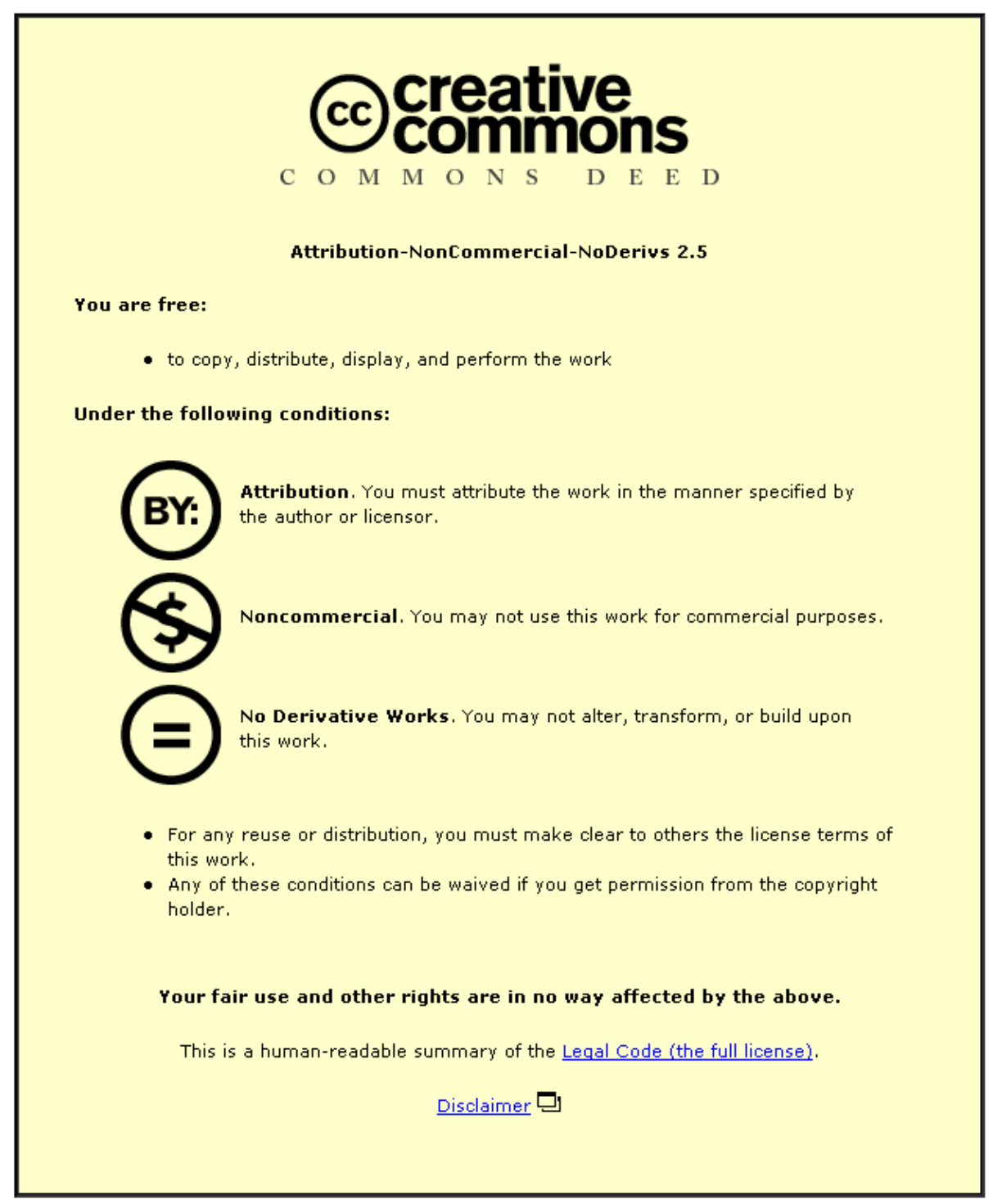

For the full text of this licence, please go to: http://creativecommons.org/licenses/by-nc-nd/2.5/ 


\title{
LQG control for the integrated tilt and active lateral secondary suspension in high speed railway vehicles
}

\author{
Ronghui Zhou, Argyrios Zolotas and Roger Goodall
}

\begin{abstract}
The paper deals with the tilt control performance of high speed railway vehicles. In particular it discusses the integration of active tilt control with an active lateral secondary suspension solution using LQG control design. The tuning of the weighting matrices of the LQG controller, for the aforementioned dual-actuator system, is accomplished using Genetic Algorithms based upon minimizing given tilting performance metrics. Issues of vehicle modeling and practical tilting performance are also included. The solution is validated via appropriate simulations and comparison with a conventional (tilt-only) precedence controller which provides a performance benchmark for the local control strategies.
\end{abstract}

\section{INTRODUCTION}

Tilting trains operate at increased speeds compared to conventional trains, without the need to upgrade the rail infrastructure. The idea is straightforward, i.e. tilting the vehicle body inwards on the curved sections of the track to compensate the large lateral acceleration perceived by passengers at higher speeds. Tilt is a rather mature technology and is well established for practical service operation. Early passive tilting trains relied on the natural pendulum motion laws which introduced safety issues [1]. Active tilting trains utilize an active roll secondary suspension system to tilt the vehicle body in order to anticipate the track profile (i.e. using some form of preview information for the tilt controllers), and it is the main technology used in trains worldwide.

For the tilting control system, the most intuitive control strategy is known as nulling control, in which the body lateral acceleration is measured and used as the feedback signal driving the single tilt actuator, so that the acceleration is reduced to zero (i.e. 100\% tilt compensation). However, a pure nulling strategy has been found to cause motion sickness [2]. Thus, the basic nulling strategy is modified by introducing a proportion of the secondary suspension roll angle to give partial tilt (60\%-70\% compensation), as shown in Fig. 1. There is a more profound problem with the lateral suspension, because the roll and lateral modes of the vehicle body are strongly coupled in a dynamic sense.

The industrial sector nowadays adopts a rather complex in nature control structure called "precedence control". In this

This work is supported by the Department of Electronic and Electrical Engineering, Loughborough University, UK.

R. Zhou is a Ph.D student with the Control systems group, Department of Electronic and Electrical Engineering, Loughborough University, Loughborough, LE11 3TU, UK r. zhoul lboro.ac.uk

A. C. Zolotas is a senior lecturer with the Control systems group, Department of Electronic and Electrical Engineering, Loughborough University, Loughborough, LE11 3TU, UK a.c.zolotas@ lboro.ac.uk

R. M. Goodall is a professor with the Control systems group, Department of Electronic and Electrical Engineering, Loughborough University, Loughborough, LE11 3TU, UK r.m.goodallelboro.ac.uk strategy, the bogie-mounted lateral accelerometer from the front vehicle is used to provide "precedence" information which avoids the lateral and roll dynamic interaction problem. Appropriate low pass filters are employed to attenuate the high frequency signal caused by the track irregularity response of the bogie. The delay introduced by the filter is compensated by the carefully designed precedence control strategy. Fig. 2 illustrates the configuration of the precedence control strategy.

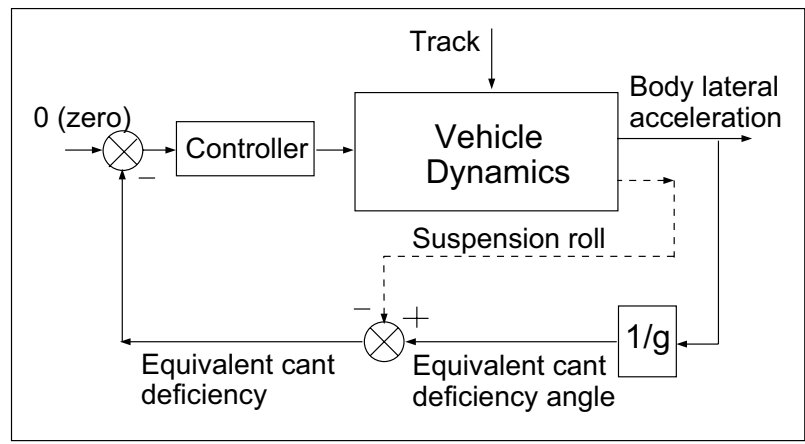

Fig. 1. Intuitive nulling control (modified)

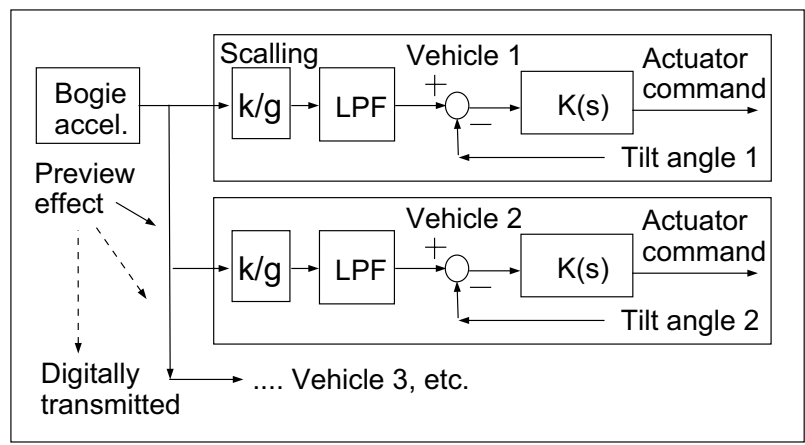

Fig. 2. Precedence command driven control

Although precedence control is an accepted commercial solution for the tilting train, research on local tilt control still has practical benefits which make the system simpler and more straightforward in terms of detecting sensor failure.

Research work described in [3][4] proposed tilt control based on local vehicle body signals with $H_{\infty}$ and Fuzzy logic controllers, but due to the dynamic interaction between roll and lateral modes of the railway vehicle body, there is further research potential of improving the overall transient performance. In addition, the high speeds associated with 
tilting trains result in worse ride quality on straight track. An active lateral secondary suspension can be integrated into the tilting train to enhance the tilting system performance, with the objectives to further improve the straight track ride quality of tilting trains and limit the dynamic interaction between lateral and roll modes of the vehicle body.

Work in [5] initially studied decentralized control strategies for the dual-actuator system (tilt and lateral actuators), but control loop interaction limits the improvement of tilt performance. In this paper, Linear Quadratic Gaussian (LQG) centralized control is applied to overcome the limit in the classical decentralized approach.

The remainder of this paper is organized as follows: Part II presents the vehicle model and track inputs. Control system performance requirements and assessment approaches are presented in Part III. Part IV refers to the basics of classical decentralized control system configuration, while Part V gives the details of the LQG control design and Genetic Algorithms (GA) tuning process. This is followed by the simulation results and discussion. Conclusions and future work are discussed in the last part.

\section{THE END-VIEW MODEL}

The simplified mechanical configuration of the integrated tilt and lateral system is shown in Fig. 3. Active Anti-Roll Bar (ARB) [6] is utilized to tilt the vehicle body. The lateral actuator is installed between the vehicle body and bogie, in parallel with the original secondary damper. The end-view

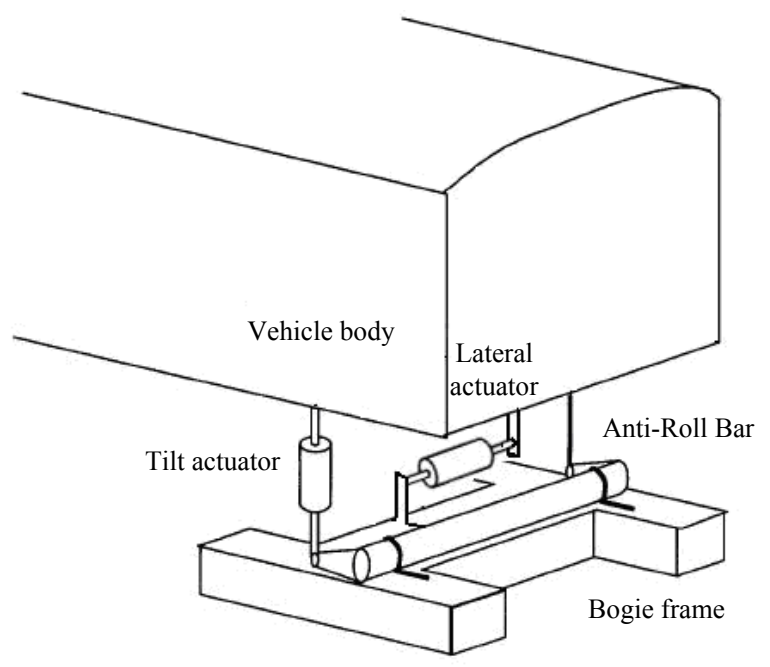

Fig. 3. The integration of roll and lateral actuators

model consists of a four degree-of-freedom dynamic system, illustrated in Fig. 4. The lateral and roll degrees of freedom for both the body and the bogie systems are included, while the vertical degrees of freedom are ignored, although the effects of the roll stiffness and damping introduced by the vertical suspension are included for completeness. A rotational displacement actuator shown by $\delta_{a}$ is included in series with the roll stiffness. Moreover, a lateral actuator shown by $F_{a}$ is installed in parallel with the original lateral damper between the bogie and the body. Both the actuators are assumed to be ideal for the purposes of this work, i.e. their dynamics are ignored. For simplicity wheelset dynamics are also ignored. Further details about the model can be found in [5]. The parameters used in this paper are list in the Appendix. The equations of motion are:

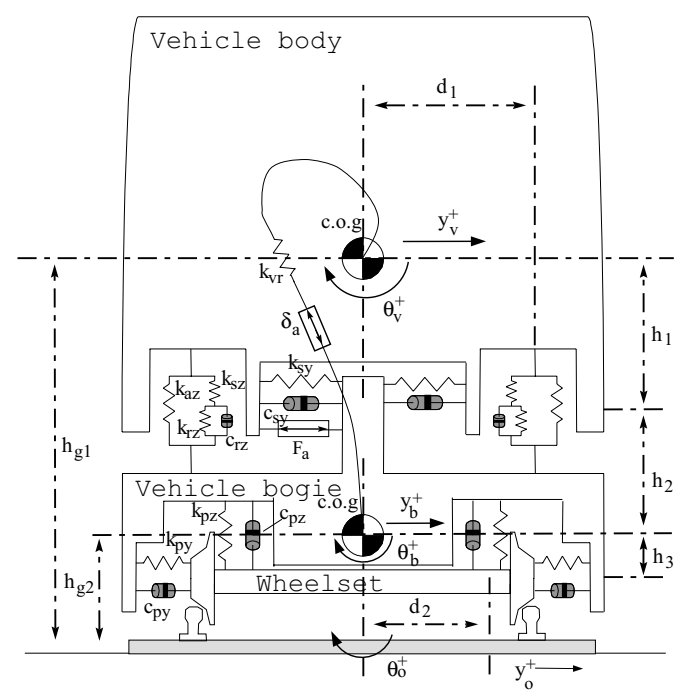

Fig. 4. Model of tilting train with lateral actuator

Body lateral dynamics:

$$
\begin{aligned}
m_{v} \ddot{y}_{v}= & -2 k_{s y}\left(y_{v}-h_{1} \theta_{v}-y_{b}-h_{2} \theta_{b}\right) \\
& -2 c_{s y}\left(\dot{y}_{v}-h_{1} \dot{\theta}_{v}-\dot{y}_{b}-h_{2} \dot{\theta}_{b}\right) \\
& -\frac{m_{v} v^{2}}{R}+m_{v} g \theta_{0}-h_{g 1} m_{v} \ddot{\theta}_{0}+F_{a}
\end{aligned}
$$

Body roll dynamics:

$$
\begin{aligned}
i_{v r} \ddot{\theta}_{v}= & 2 h_{1} k_{s y}\left(y_{v}-h_{1} \theta_{v}-y_{b}-h_{2} \theta_{b}\right)+2 h_{1} c_{s y}\left(\dot{y}_{v}\right. \\
& \left.-h_{1} \dot{\theta}_{v}-\dot{y}_{b}-h_{2} \dot{\theta}_{b}\right)-k_{v r}\left(\theta_{v}-\theta_{b}-\delta_{a}\right) \\
& +m_{v} g\left(y_{v}-y_{b}\right)-2 d_{1}{ }^{2} k_{a z}\left(\theta_{v}-\theta_{b}\right) \\
& -2 d_{1}{ }^{2} k_{s z}\left(\theta_{v}-\theta_{r}\right)-i_{v r} \ddot{\theta}_{0}-F_{a} h_{1}
\end{aligned}
$$

Bogie lateral dynamics:

$$
\begin{aligned}
m_{v} \ddot{y}_{b}= & 2 k_{s y}\left(y_{v}-h_{1} \theta_{v}-y_{b}-h_{2} \theta_{b}\right)+2 c_{s y}\left(\dot{y}_{v}-h_{1} \dot{\theta}_{v}\right. \\
& \left.-\dot{y}_{b}-h_{2} \dot{\theta}_{b}\right)+2 k_{p y}\left(y_{b}-h_{3} \theta_{b}-y_{0}\right)-2 c_{p y}\left(\dot{y}_{b}\right. \\
& \left.-h_{3} \dot{\theta}_{b} \dot{y}_{0}\right)-\frac{m_{v} v^{2}}{R}+m_{v} g \theta_{0}-h_{g 1} m_{v} \ddot{\theta}_{0}-F_{a}
\end{aligned}
$$

Bogie roll dynamics:

$$
\begin{aligned}
i_{b r} \ddot{\theta}_{b}= & 2 h_{2} k_{s y}\left(y_{v}-h_{1} \theta_{v}-y_{b}-h_{2} \theta_{b}\right)+2 h_{2} c_{s y}\left(\dot{y}_{v}\right. \\
& \left.-h_{1} \dot{\theta}_{v}-\dot{y}_{b}-h_{2} \dot{\theta}_{b}\right)-2 h_{3}\left(k_{p y}\left(y_{b}-h_{3} \theta_{b}-y_{0}\right)\right. \\
& \left.+c_{p y}\left(\dot{y}_{b}-h_{3} \dot{\theta}_{b} \dot{y}_{0}\right)\right)+k_{v r}\left(\theta_{v}-\theta_{b}-\delta_{a}\right) \\
& +2 d_{1}^{2}\left(k_{a z}\left(\theta_{v}-\theta_{b}\right)+k_{s z}\left(\theta_{v}-\theta_{r}\right)\right) \\
& -2 d_{2}{ }^{2}\left(k_{p z} \theta_{b}+c_{p} z \dot{\theta}_{b}\right)-i_{b r} \ddot{\theta}_{0}-F_{a} h_{2}
\end{aligned}
$$

for the additional air-spring state:

$$
\dot{\theta}_{r}=-\frac{k_{s z}+k_{r z}}{c_{r z}} \theta_{r}+\frac{k_{s z}}{c_{r z}} \theta_{v}+\frac{k_{r z}}{c_{r z}} \theta_{b}+\dot{\theta}_{b}
$$


The vehicle model and control system are tested with specific track inputs including both deterministic (low frequency signals) and stochastic (high frequency signals) features. The deterministic track input was a curved track with a radius of $1000 \mathrm{~m}$ and a maximum track cant angle $\left(\theta_{0 \max }\right)$ of $6^{0}$, with a transition $(150(\mathrm{~m}))$ at the start and end of the steady curve. The stochastic track inputs represent the irregularities in the track alignment on both straight track and curves, and these were characterised by an approximate spatial spectrum equal to $(2 \pi)^{2} \Omega_{l} v^{2} / f_{t}\left(m^{2} /(\right.$ cycle $\left./ m)\right)$ with a lateral track roughness $\left(\Omega_{l}\right)$ of $0.33 \times 10^{-8}(m)$ [3].

\section{CONTROLLER PERFORMANCE ASSESSMENT}

The dual-actuator system controller design needs to meet both tilt performance and lateral suspension requirements [7]. Two main design criterion are summarized as follows:

(i) Provide a fast response on curved track (deterministic criterion) which is divided into two aspects:

- $P_{c t}$ value for the curve transitions: this is a criterion on quasi-static lateral acceleration and lateral jerk perceived by the passengers and was suggested by a British Rail research study, see [8]. It indicates the percentage of passengers who will feel uncomfortable as a result of the transition onto the curve, calculated via a non-linear formula.

- Investigation of the transitional dynamic suspension effects based upon the "ideal tilting" approach [9], a technique which essentially quantifies how closely a particular control solution fits to the ideal response.

(ii) Maintain good ride quality in response to track irregularities on straight track (stochastic criterion). The root Mean Square (R.M.S.) value of the body lateral acceleration on straight track in response to the track irregularities is traditionally utilized to assess the straight track performance. More information about tilting train control assessment can be found in [9]. Associated with ride quality improvement is the constraint on lateral suspension deflection, which should not exceed the maximum available before bump stops are reached, i.e. $\pm 60(\mathrm{~mm})$ is used in this study.

\section{CLASSICAL DECENTRALIZED CONTROL}

The classical decentralized control approach is summarized in the following. The driving signal for the tilting action is the effective cant deficiency ${ }^{1}$ :

$$
\theta_{d m}=-k_{1} \ddot{y}_{v m} / g-k_{2} \theta_{2 s r}
$$

where $\ddot{y}_{v m}$ is the measured body lateral acceleration, $\theta_{2 s r}$ is the secondary suspension roll angle:

$$
\begin{aligned}
& \ddot{y}_{v m}=\frac{v^{2}}{R}-g\left(\theta_{0}+\theta_{v}\right)+\ddot{y}_{v} \\
& \theta_{2 s r}=\theta_{v}-\theta_{b}
\end{aligned}
$$

$k_{1}$ and $k_{2}$ are set to 0.60 and 0.40 for $60 \%$ partial tilt compensation. While $\ddot{y}_{v m}$ and the lateral secondary suspension deflection $x_{2 d f l}\left(=y_{v}-h_{1} \theta_{v}-\left(y_{b}+h_{2} \theta_{b}\right)\right)$ are feedback

\footnotetext{
${ }^{1}$ Cant deficiency is the term used to quantify the curving acceleration experienced by passengers, usually expressed as an angle - see [10] for more detail.
}

signals for the lateral actuator. Fig. 5 shows the overall system configuration.

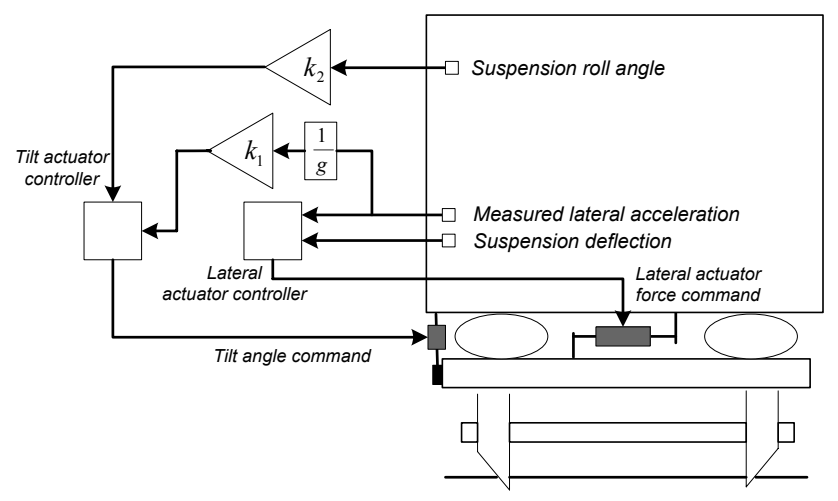

Fig. 5. Classical decentralized control system configuration

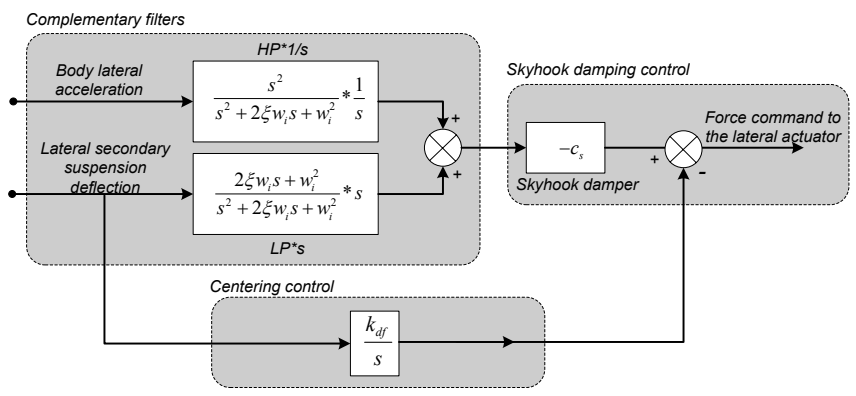

Fig. 6. Skyhook damping lateral actuator control with body lateral centering control

Sequential design process is adopted because the lateral actuator control loop is a high bandwidth strategy (to attenuate high frequency lateral irregularities) that is intended to respond faster than the tilting action.

The skyhook damping strategy with complementary filter [5][11] is employed to control the lateral actuator, as shown in Fig. 6. Further, the integral of the lateral secondary suspension deflection is added to the lateral actuator control loop, which aims to keep the suspension deflection within the limit to avoid the bump stop in the lateral direction, this is important because skyhook damping increases the suspension deflection on curves. Approximate PID control $\left(f_{A . P I D}\right)$ is employed for the tilt actuator:

$$
f_{\text {A.PID }}=\left(k_{p}+\frac{k_{i}}{s}+\frac{k_{d} s}{s / N+1}\right)
$$

The decentralized nature of the solution, although simple, and the strong interaction between the lateral and roll direction unfortunately limit the performance improvement. A further centralized LQG solution is presented next.

\section{LQG CENTRALIZED CONTROL}

Compared with the decentralized control, optimal control allows for direct use of the MIMO state space model thus allowing for any couplings in the states during the design process in a centralized solution. 


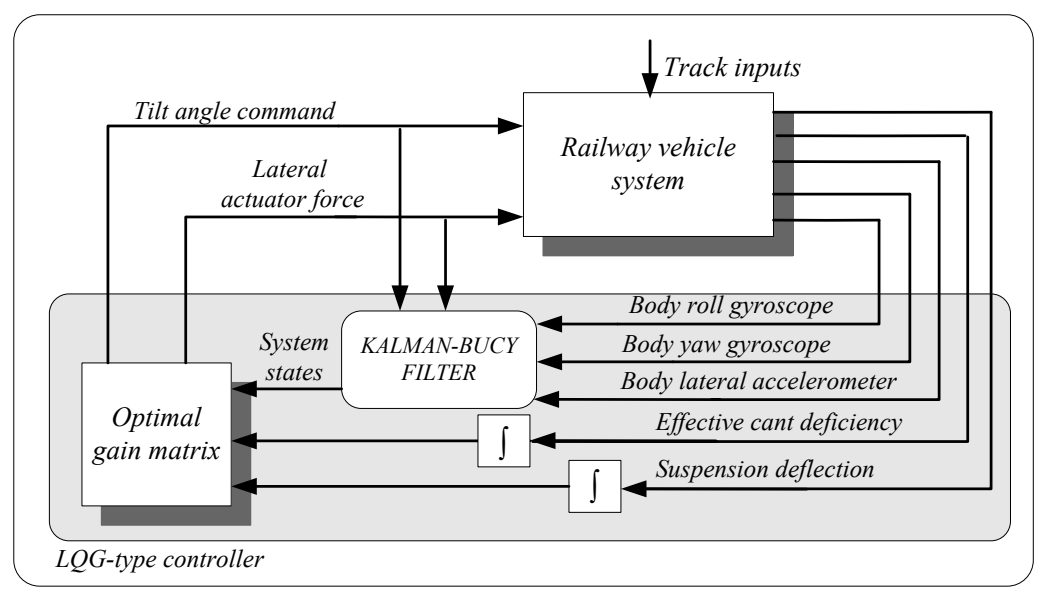

Fig. 7. LQG control system

The Linear Quadratic Regulator (LQR) is an optimal control design method that yields a full state feedback controller which minimizes the quadratic performance index (using output regulation):

$$
J=\int_{0}^{T}\left[z^{T} Q_{0} z+u^{T} R_{0} u\right] d \tau
$$

The controller design process involves selecting the outputs to be weighted $(\mathrm{z})$, and tuning the system output and control input weighting factors $\left(Q_{0}, R_{0}\right)$. In the case where all required system states are not available for feedback, which may be difficult, impractical or sometimes not possible to measure, a Kalman filter can be combined with the optimal controller to provide the necessary state estimates for state feedback. This is the well known Linear Quadratic Gaussian (LQG) problem [12]. The overall system structure is illustrated in Fig. 7. The controller is designed via the separation principle.

\section{A. LQR design}

The following states are selected: body lateral displacement, body roll angle, bogie lateral displacement, bogie roll angle, body lateral displacement velocity, body roll rate, bogie lateral displacement velocity, bogie roll rate and air spring roll angle. In addition, the integral of $\theta_{d m}$ (effective cant deficiency) is combined into the states for disturbance rejection and reference tracking. Also, the integral of $x_{2 d f l}$ (Lateral secondary suspension deflection) is required to avoid the lateral bump stop. Hence, the system is augmented to include $\left(\int \theta_{d m}, \int x_{2 d f l}\right)$ as extra states. The state vector is given by:

$$
x=\left[\begin{array}{llllllllllll}
y_{v} & \theta_{v} & y_{b} & \theta_{b} & \dot{y}_{v} & \dot{\theta}_{v} & \dot{y}_{b} & \dot{\theta}_{b} & \theta_{r} & \int \theta_{d m} & \int x_{2 d f l}
\end{array}\right]
$$

The weighted outputs selected are the body roll rate, $\int \theta_{d m}, \int x_{2 d f l}$. The output weighting factor $Q_{0}$ and control weighting factor $R_{0}$ can be initially set to $1 /(\text { signal expected value })^{2}$ (using Bryson's rule) with further fine tuning required. In particular, GA techniques are utilized in this work for tuning the weighting matrices subject to satisfying given tilt performance metrics.

\section{B. GA optimization}

Nondominated Sorting Genetic Algorithm NSGA II [13] is used to tune the weighting factor $Q_{0}$ and $R_{0}$. The optimization process is based on the principles of natural evolution and population genetics, a set of non-dominated solutions can be obtained after the optimization.

Setting the objective functions and initial optimization boundary for the parameters are the main issues for the GA. In this study, the optimization boundary set for the tilting control weighting is from $1 /(0.1745)^{2}$ to $1 /(0.05)^{2}$. The vehicle body tilt angle is expected in the range 2.8 degrees10 degrees. $1 /(20000)^{2}$ to $1 /(8000)^{2}$ is set for the lateral actuator force command. The large lateral force is required particularly when the train negotiates the curve. The initial boundaries can be set in the similar way for the output weighting function,

$$
\left.Q_{0}=\operatorname{diag}\left(\left[\frac{1}{0.15^{2}} \text { to } \frac{1}{0.05^{2}}\right],\left[\frac{1}{0.01^{2}} \text { to } \frac{1}{0.001^{2}}\right]\right),\left[\frac{1}{0.06^{2}} \text { to } \frac{1}{0.01^{2}}\right]\right)
$$

The following objective functions are defined with the consideration of curving performance and straight track ride quality requirement.

(1) $O b j_{1}=P_{c t}$ value for the standing passenger, which is for the curving performance.

(2) $O b j_{2}=$ R.M.S. value of the vehicle body lateral acceleration, which is for the ride quality on the straight track.

(3) $\mathrm{Obj}_{3}=$ R.M.S. value of the deviation error between the actual lateral acceleration compared with the ideal acceleration

(4) $\mathrm{Obj}_{4}=$ R.M.S. value of the deviation error between the actual body roll rate compared with the ideal roll rate.

$\mathrm{Obj}_{3}$ and $\mathrm{Obj}_{4}$ are used to identify what a tilting vehicle would ideally perform on the transition from straight to curved track [9]; Constraint for the NSGA_II optimization is set as the suspension deflection limit $(60(\mathrm{~mm}))$.

Fig. 8 shows the trade-off for the controller design between curving performance and straight track ride quality. Also, the optimization process is illustrated. We give the results for 200 and 500 generations with 30 populations. The final weightings for the best design are chosen to be:

$$
Q_{0}=\operatorname{diag}\left(\frac{1}{0.0574^{2}}, \frac{1}{0.0052^{2}}, \frac{1}{0.01745^{2}}\right)
$$




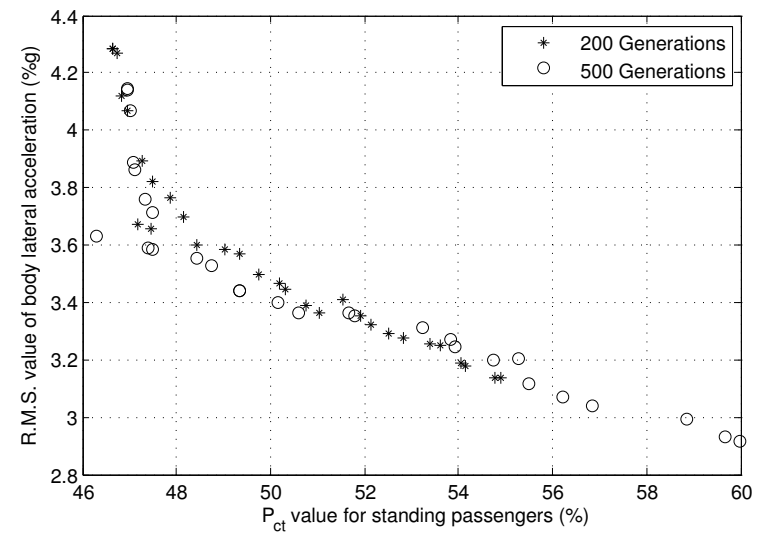

Fig. 8. GA tuning results for LQG control

$$
R_{0}=\operatorname{diag}\left(\frac{1}{0.1655^{2}}, \frac{1}{12958^{2}}\right)
$$

And the final optimal gain $K$ :

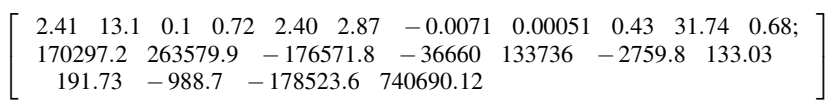

Note that the large gain exists in the second row for the lateral actuator force command, due to the relatively large lateral actuator forces compared with the drive signal for the tilting action.

\section{Kalman-Bucy Filter $(K B F)$ design}

$\mathrm{KBF}$ is used as the optimal state estimator. The inputs to the $\mathrm{KBF}$ are the two system inputs and three measurements: vehicle body roll gyroscope (cant information), body lateral accelerometer (for cant deficiency information) and vehicle body yaw gyroscope (required only for extra information on the curvature $R^{-1}$ ). The body roll gyroscope measures absolute roll rate $\left(\dot{\theta}_{v}+\dot{\theta}_{0}\right)$, thus $\dot{\theta}_{0}$ must also be included in the state estimates. The system state space can be reformulated for the design of the KBF in order to treat parts of disturbance $\left(\theta_{0}, \dot{\theta}_{0}, R^{-1}\right)$ as states. The reformulated state vector for the estimation is:

$$
x=\left[\begin{array}{llllllllllll}
y_{v} & \theta_{v} & y_{b} & \theta_{b} & \dot{y}_{v} & \dot{\theta}_{v} & \dot{y}_{b} & \dot{\theta}_{b} & \theta_{r} & \theta_{0} & \dot{\theta}_{0} & R^{-1}
\end{array}\right]^{\prime}
$$

The process noise is characterized by $w=\left[\begin{array}{ll}\dot{R}^{-1} & \dot{\theta}_{0}\end{array}\right]^{\prime}$, the two inputs are $\left[\begin{array}{ll}\delta_{a} & F_{a}\end{array}\right]^{\prime}$. The KBF can be designed offline using (10) and (11).

$$
\begin{gathered}
\dot{x}_{k f}=A_{k f} x_{k f}+B_{k f} u+\Gamma_{k} w_{k} \\
y_{k f}=C_{k f} x_{k f}+D_{k f} u+v
\end{gathered}
$$

while the state estimates will be calculated by solving the following differential equation:

$$
\dot{\hat{x}}=A_{k} \widehat{x}+B_{k} u+K_{f}\left(y_{k}-C_{k} \widehat{x}-D_{k} u\right)
$$

where $\widehat{x}$ is the vector of the state estimates and $K_{f}$ is the KBF gain matrix. The sensor noise levels are characterized by a covariance matrix with each diagonal value is set to $1 \%$ of the expected maximum value taken as, 3 times the true R.M.S. value of the sensor output signal on straight track with irregularities, plus the peak value on the pure curved track. Sensor noise covariance and process noise covariance are to be as follows,

$$
\begin{gathered}
R=\operatorname{diag}\left(1.62 \times 10^{-3}, 1.88 \times 10^{-6}, 1 \times 10^{-6}\right) \\
Q=\operatorname{diag}\left(\frac{1}{0.1655^{2}}, \frac{1}{12958^{2}}\right)
\end{gathered}
$$

Final Kalman gain $K_{f}$ is:

$$
\left[\begin{array}{rrr}
-0.2417 & -2.4557 & -0.2671 ; \\
-0.0900 & -2.6223 & 0.0160 \\
0.0020 & 0.0994 & -0.1718 \\
-0.0379 & -1.0614 & 0.0221 \\
-1.0787 & 7.1346 & -57.5770 \\
-0.4257 & 0.7823 & -0.0504 ; \\
0.0460 & -0.0593 & -31.4448 ; \\
-0.1723 & 0.2823 & 2.7934 \\
-0.0687 & -2.1104 & 0.0263 ; \\
0.0631 & 4.2355 & -0.0101 \\
0.4439 & 16.7855 & -0.0774 \\
0.0004 & -0.0012 & 3.1622
\end{array}\right]
$$

\section{SIMULATION RESULT AND DISCUSSION}

The closed-loop system is simulated using the specific track from Part II with the vehicle forward speed $58 \mathrm{~m} / \mathrm{s}$. The simulation results and assessment value are illustrated in Fig. 9, Fig. 10 and Table 1 respectively.

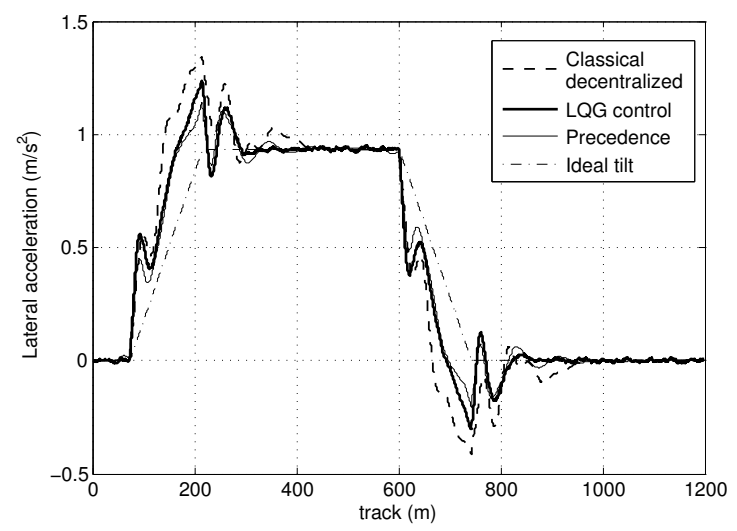

Fig. 9. Measured body lateral acceleration

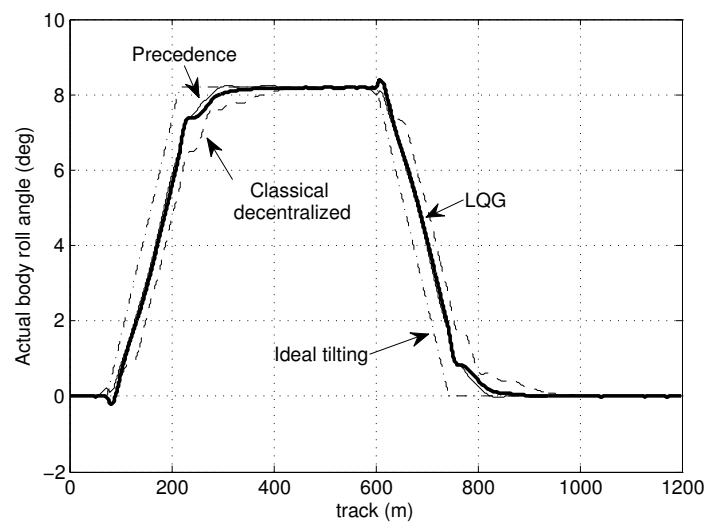

Fig. 10. Actual body roll angle

As discussed in Part III, one of the requirements for tilting control is to minimize the deviation between the real tilt response and expected ideal tilt action. Fig. 9 shows the dynamic process for the measured body lateral acceleration 
during curving. $60 \%$ lateral acceleration compensation is required. The performance of the LQG control is very similar to the industrial-used precedence control, which is of course closer to the ideal response. Note that the precedence control used in this work relates to the single tilt actuator as used in commercial tilting trains. The R.M.S. deviation error of the lateral acceleration is $1.3 \% \mathrm{~g}$, which is less than the value for the precedence control, as shown in Table 1.

The assessment is also performed by comparison of the $P_{c t}$ values (for curving transition performance) and R.M.S. value of the body lateral acceleration (for straight track ride quality). The $P_{c t}$ value of the LQG control for the seated passenger is $12.8 \%$, which is slightly less than the value for the precedence control. Also the improvement on straight track is illustrated by the R.M.S. value of $3.63 \% \mathrm{~g}$ which gives $4 \%$ improvement compared to the passive value (nontilting, with passive suspension). Note that the precedence controller has an advantage due to the previous information. The actual body roll angle with the LQG control is also close to the ideal one, which is shown in Fig. 10.

\section{TABLE I}

CONTROL SYSTEM CONFIGURATION ASSESSMENT FOR TILTING TRAIN WITH ACTIVE ANTI-ROLL BAR (a) 58( $\mathrm{m} / \mathrm{s}$ ) (REFER TO [3] FOR THE PRECEDENCE CONTROL)

\begin{tabular}{|c|c|c|c|}
\hline Deterministic (CURVED TRACK) & $\begin{array}{c}\text { Classical } \\
\text { decentralized }\end{array}$ & LQG & Precedence \\
\hline Lateral acceleration: & & & \\
\cline { 2 - 4 } -Steady-state (\%g) & 9.53 & 9.53 & 9.53 \\
\cline { 2 - 4 } -R.M.S. deviation error (\%g) & 4.60 & 1.30 & 1.52 \\
\cline { 2 - 4 } -Peak value (\%g) & 13.7 & 12.6 & 12.14 \\
\cline { 2 - 4 } Roll gyroscope: & & & \\
\cline { 2 - 4 } -R.M.S. deviation (rad/s) & 0.021 & 0.016 & 0.022 \\
\cline { 2 - 4 } -Peak value (rad/s) & 0.106 & 0.101 & 0.103 \\
\cline { 2 - 4 }$P_{c t}$ (P-factor): & & & \\
-Peak jerk level (\%g/s) & 7.75 & 5.87 & 6.72 \\
-standing (\% of passengers) & 54.4 & 46.3 & 47.3 \\
\cline { 2 - 4 } -seated (\% of passengers) & 15.7 & 12.8 & 13.33 \\
\hline Stochastic (STRAIGHT TRACK) & \multicolumn{3}{|l}{} \\
\hline passenger comfort: & \multicolumn{3}{|l}{} \\
-R.M.S. passive (\%g) & 3.78 & 3.78 & 3.78 \\
\cline { 2 - 4 } -R.M.S. active (\%g) & 3.69 & 3.63 & 3.22 \\
\cline { 2 - 4 } -degradation (\%) & -2.38 & -4 & -12.12 \\
\hline
\end{tabular}

\section{CONCLUSIONS AND FUTURE WORKS}

In this paper, the LQG centralized control for the integrated tilt and active lateral secondary suspension is discussed. It aims to overcome the control loop interactions in the decentralized control and further improve the performance of using the local integrated suspension control. The simulation results show these objectives can be achieved. The performance of the LQG centralized control is very similar as the precedence control.

The simulation results illustrate that the local tilt control system is able to achieve a similar performance to the precedence control, providing a simpler solution. Further work is to be carried out on system robustness analysis particularly for parametric uncertainty.

\section{APPENDIX}

\section{A. NOTATION OF THE MODEL}

$y_{v}, y_{b}, y_{0}$ Lateral displacement of body, bogie and track $\theta_{v}, \theta_{b}, \delta_{a}$ Roll displacement of body, bogie and actuator

$\theta_{0}, R \quad$ Track cant, curve radius

$\theta_{r} \quad$ Airspring reservoir roll defection

$v \quad$ Vehicle forward speed $(\mathrm{m} / \mathrm{s})$

$m_{v} \quad$ Half body mass, 19,000 $(\mathrm{kg})$

$i_{b r} \quad$ Bogie roll inertia, 1,500 $\left(\mathrm{kgm}^{2}\right)$

$k_{a z} \quad$ Airspring area stiff., 210,000 $(\mathrm{N} / \mathrm{m})$

$k_{s z} \quad$ Airspring series stiff., 620,000 $(\mathrm{N} / \mathrm{m})$

$k_{r z} \quad$ Airspring reserv. stiff., 244,000 $(\mathrm{N} / \mathrm{m})$

$c_{r z} \quad$ Airspring reserv. damp., 33,000 $((\mathrm{Ns}) / \mathrm{m})$

$k_{s y} \quad$ Secondary lateral stiff., 260,000 $(\mathrm{N} / \mathrm{m})$

$k_{v r} \quad$ Anti-roll bar stiff./bogie, 2,000,000 $((\mathrm{Nm}) / \mathrm{rad})$

$k_{p z} \quad$ Primary vertical stiff., 2,000,000 $(\mathrm{N} / \mathrm{m})$

$c_{p z} \quad$ Primary vertical damp., 20,000 $((N s) / m)$

$k_{p y} \quad$ Primary lateral stiff., 35,000,000 $(\mathrm{N} / \mathrm{m})$

$c_{p y} \quad$ Primary lateral damp., 16,000 $((\mathrm{Ns}) / \mathrm{m})$

$d_{1} \quad$ Airspring semi-spacing, $0.90(\mathrm{~m})$

$d_{2} \quad$ Prim. vert. suspen. semi-spacing, $1.00(\mathrm{~m})$

$h_{1} \quad$ 2ndary later. suspen. height (body cog), $0.9(\mathrm{~m})$

$h_{2} \quad$ 2ndary later. suspen. height (bogie cog), $0.25(\mathrm{~m})$

$h_{3} \quad$ Primary later. suspen. height (bogie cog), $0.09(\mathrm{~m})$

$h_{g 1} \quad$ Bogie cog height (above rail level), $0.37(\mathrm{~m})$

$h_{g 2} \quad$ Body cog height (above rail level), $1.52(\mathrm{~m})$

$i_{v r} \quad$ Half body roll inertia, 25,000 $\left(\mathrm{kgm}^{2}\right)$

$m_{b} \quad$ Bogie mass, 2,500 $(\mathrm{kg})$

\section{REFERENCES}

[1] R. Persson, Tilting trains Technology, benefits and motion sickness, Licentiate Thesis, Railway Technology, Stockholm, Sweden 2008.

[2] R. M. Goodall, "Tilting trains and beyond - the future for active railwaysuspensions: Part 1 Improving passenger comfort", Computing an Control Engineering Journal, vol.10, no.4, 1999, pp 153-160.

[3] A. C. Zolotas, R. M. Goodall, "Modelling and control of railway vehiclesuspensions", Lecture notes in control and information sciences, vol.367, 2007, pp 373-412.

[4] H. Zamzuri, A. C. Zolotas, and R. M. Goodall, "Tilt control design for high-speed trains: a study on multi-objective tuning approaches", Vehicle System Dynamics, vol.46, no.1, 2008, pp 535-547.

[5] R. Zhou, A. C. Zolotas, and R. M. Goodall, "Integrated tilt and active lateral secondary suspension control", Proceedings of the 5th international symposium on speed-up, safety and service technology for rail-way and maglev systems (STECH'09), Japan, June 2009.

[6] J. T. Pearson, R. M. Goodall, and I. Pratt, "Control system studies of an active anti-roll bar tilt system for railway vehicles", Proceedings of the Institution of Mechanical Engineers, 212 no.F1, 1998, pp 43-60.

[7] R. M. Goodall, T.X. Mei, Active suspensions, Chapter 11 in Handbook of Railway Vehicle Dynamics, (Taylor and Francis). 2006.

[8] CEN: (2007), Railway applications-Ride comfort for passengers Measurements and evaluation, enquiry version pr EN12299.CEN. Brussels.

[9] R. M. Goodall, A. C. Zolotas, and J. Evans, "Assessment of the Performance of Tilt System Controllers", The Railway Conference a Railtex 2000, NEC Birmingham, UK, November 2000.

[10] "Cant deficiency". Available: http://en.wikipedia.org/wiki/Cant_deficiency.

[11] H. Li, R. M. Goodall, "Linear and non-linear skyhook damping control laws for active railway suspensions", Control Engineering Practice, vol7, no7, 1999, pp 843-850.

[12] S. Skogestad, I. Postlethwaite, Multivariable feedback control: Analysis and design, Wiley, 2000, Reprinted Version.

[13] N. Srinivas and K. Deb, "Multiobjective optimization using nondominated sorting in genetic algorithms", Evolutionary computation, vol2, 1994, pp 221-248. 